good of all, and above all, for the protection of the weak." I submit that, no matter how appealing a marketplace model may seem for the NHS, it is a business model. As such the destruction of either purchaser or provider is eventually certain, with the barbarisation of the survivor.

It is not too late for consortiums of purchasers and consortiums of providers to join forces and become one NHS again.

Walsgrave Hospital NHS Trust,

LAURENCE WOOD Coventry CV2 2DX

1 Klein R. Health care reform: the global search for utopia. $B M$ 1993;307:752. (25 September.)

2 Cronin DP. Words of wisdom. Slough: St Paul's Publications, 1990.

\section{Natural family planning}

\section{Depends on consumers not providers}

EDITOR,-In his letter on natural family planning James Trussell mentions safety and efficacy. Safety is not synonymous with efficacy. Guillebaud stated:

We can reduce, but by definition we can never remove all the risks from any systemic method. Without fear of contradiction during the next 100 years, one can say that no chemical, steroidal, non-steroidal or antigenic can be devised which, whether given to women or men, whether administered precoitally or postcoitally or whether used by the oral, nasal, retinal, cutaneous, subcutaneous, rectal or vaginal routes will be totally free of all risk. Anything that gets into the blood stream must be capable of causing harmful effect somewhere, yet the scientific establishment have so far concentrated overwhelmingly on these very systemic methods . . . the search for the impossible a risk free systemic method. ${ }^{2}$

In a poor rural area of Ethiopia between 1982 and 1990 the crude birth rate fell from 38 to 16.6 per 1000 population and the fertility rate from 159 to 77 per 1000 fertile women. ${ }^{3}$ These decrease were attributable to an immunisation programme, more children surviving, and the use of natural family planning - truly preventive medicine.

Matthew D Barber's plea for more artificial contraception to prevent pregnancy in young women is not supported by facts.' In Britain during the past 20 years contraception has never been more freely available irrespective of age, marital status, or parental consent, yet the abortion rate continues to rise, especially in young women The only time that the conception and abortion rates in young women did not rise as had been predicted was when children were required to have parental permission before they could receive contraceptives (the rate of uptake of contraception in young people fell by a third). The rise in abortion was predicted by Potts of the International Planned Parenthood Federation in $1973^{4}$ and by Bury of the Brook Advisory Centre in 1981, who stated, "There is overwhelming evidence that, contrary to what you might expect, the availability of contraception leads to an increase in the abortion rate."

Anne Jewell ${ }^{1}$ and John Guillebaud ${ }^{1}$ erroneously imply that sexual arousal is greatest at ovulation. Arousal depends on many factors irrespective of the time in the cycle. In many women the combined pill inhibits ovulation, yet only a minority of women taking this pill complain of loss of libido.

When discussing attempts at developing a condom made of plastic Population Reports stated, "While a more expensive material than latex plastic is more uniform with fewer pinholes or variations in thickness." The same issue quoted a recent analysis (for the World Health Organisation) of data from 10 studies on the transmission of HIV, which found a relative risk of 0.4 for people using condoms-that is, $10 \%$ of the risk for people not using condoms.

Scientific natural family planning depends on consumers rather than providers and so will not be welcomed by population controllers.

JOHN KELLY

Natural Family Planning Centre,

Birmingham Maternity Hospital

Birmingham B15 2TG

1 Correspondence. Natural family planning. BMf 1993;307: 1003-5. (16 October.)

2 Guillebaud J. Present and future trends in contraception. British fournal of Family Planning 1988;13:2-8.

3 Webster F. Evaluation of the public health and development programme, Attat Hospital, 1982 to 1990. Ethiopia: Attat Hospital, 1990.

4 Potts M. Cambridge Evening News 1973 Feb 7.

5 Bury J. Sex education for bureaucrats. Scotsman 1981 Jun 29.

6 New condoms in the 1990s. Popul Rep [H] 1990;8:23-31.

\section{Unplanned pregnancy rates declining}

EDrToR,-R E J Ryder correctly points out that natural family planning can be a highly effective means of avoiding pregnancy. ${ }^{1}$ Over the past decade improvements in teaching programmes and the delivery of services have greatly lowered the rates of unplanned pregnancy among people using natural family planning in both developed countries and Third World countries. ${ }^{2}$ A Pearl index (pregnancies per 100 woman years) of between 2 and 4 is commonly reported for the more recent studies of both the symptothermal and the ovulation methods. ${ }^{2}$ These acceptable values undoubtedly represent optimum results: rates of unplanned pregnancy will be higher in real life than in research studies, but so too are they when oral contraceptive and barrier methods are used.

The World Health Organisation's multicentre study of the ovulation method of natural family planning, for which I was a principal investigator, showed that couples could be taught to recognise and understand the symptoms of the fertile period of the menstrual cycle irrespective of their culture or level of education. ${ }^{3}$ The suitability of natural methods of family planning for Third World countries should therefore not be denigrated because of misinformed or outdated beliefs on their impracticality and poor effectiveness. Indeed, natural family planning should be a family planning option in the health system of all countries.

JOHN FRANCE

Department of Obstetrics and Gynaecology,

University of Auckland,

School of Medicine,

Auckland,

1 Ryder REJ. "Natural family planning"; effective birth control supported by the Catholic church. BMF 1993:307:723-6. (18 supported by

2 Kambic RT. Natural family planning use-effectiveness and continuation. Am $\mathcal{F}$ Obstet Gynecol 1991;165:2046-8.

World Health Organisation. A prospective multicentre trial of the ovulation method of natural family planning. 1. Teaching phase. Fertil Steril 1981;36:152-8.

\section{Natural methods have cross cultural appeal}

EDITOR,-R E J Ryder's paper gives an informative overview of the steadily increasing acceptance worldwide of natural techniques for regulating fertility. ${ }^{1}$ The fierce and sometimes emotional criticism it has received ${ }^{2}$ was predictable for various reasons, not least the general ignorance of the effectiveness of modern natural techniques when they are used to achieve or avoid pregnancy and a consequent failure to recognise the possibility that in a comparatively short time these techniques will become the first choice of couples everywhere. Many of the letters mention the demand for uninterrupted availability of sexual intercourse, which is an unrealistic expectation in any marriage and sets a course for the breakdown of the marriage.

No doubt there are many people whose efforts to spread knowledge about methods of regulating births do not depend on financial or other personal benefits, who believe that most people are able to act responsibly with regard to their sexuality, and who perceive that the remainder can be helped to do so. During the past 20 years or so my wife, Evelyn, and I have spent an average of four months each year trying to establish and expand teaching centres for the Billings ovulation method in more than 100 countries. We have thus observed at first hand the ready acceptance of the method by couples of different cultures and religions, its comprehension and successful use by the poorest of the illiterate poor, and its applicability in all the different physiological circumstances and the various pathological conditions that occur during the reproductive life of the woman. Moreover, the method has important social benefits in fostering marital harmony and fidelity and in encouraging monogamous relationships amongst those who are sexually active, which is the essential education required to halt the AIDS epidemic.

Couples may choose to depart from the guidelines of any technique they adopt; that is a matter of freedom. They know that the "rules" mean what they say. Surely the rule of any technique of doing anything - for example, of using condoms and the contraceptive pill-mean what they say. The quaint terminology of some of the correspondents in describing the Billings ovulation method as "unforgiving" should not persuade anyone that some new weakness of the method has been discovered.

20 Milfay Avenue,

JJ BILLINGS

Melbourne,

Victoria 310

Australia

1 Ryder REJ. "Natural family planning"; effective birth control supported by the Catholic church. BMJ 1993;307:723-6. (18 September.)

2 Correspondence. Natural family planning. $B M \mathcal{F} 1993 ; 307: 1003-$ 5. (16 October.)

\section{Cheap, effective, and free of side effects}

EDrror,-Not unexpectedly, a flood of letters of criticism ${ }^{1}$ followed R E J Ryder's article on natural family planning. ${ }^{2}$ All the correspondents accept the main facts as Ryder states them but dispute whether natural family planning is really suitable for all, especially poor people in Third World countries.

James Trussell ${ }^{1}$ and John Guillebaud ${ }^{1}$ distinguish between perfect and imperfect use. The table in Ryder's paper showing the probability of pregnancy by the phase of the cycle (taken from the World Health Organisation's international study of natural family planning) shows that a couple can use the method to achieve a 0.667 probability of pregnancy (peak day) if they want a child, a 0.004 probability of pregnancy (outside the fertile period) if they do not, or a probability in between these figures if they want to space their children. Why should only one of these options be considered to be perfect use?

Matthew D Barber writes of the problem of premarital conception. ${ }^{1}$ Natural family planning requires a stable relationship, and its philosophy is opposed to premarital sexual intercourse. Easy availability of contraceptives, on the other hand, encourages extramarital sex. Anne Jewell speaks for women who have an unequal say in the decision to have sexual intercourse. ${ }^{1}$ That is a marital problem that should be dealt with in its own right and that contraception will not change. Ronán $M$ Conroy describes the Billings method as an intervention that demands compliance. The whole point of natural family planning is surely the absence of intervention.

Aside from the quoted advantages of natural family planning-namely, cheapness, effectiveness, and lack of side effects-there is a further advantage: discipline. The shared, self imposed 